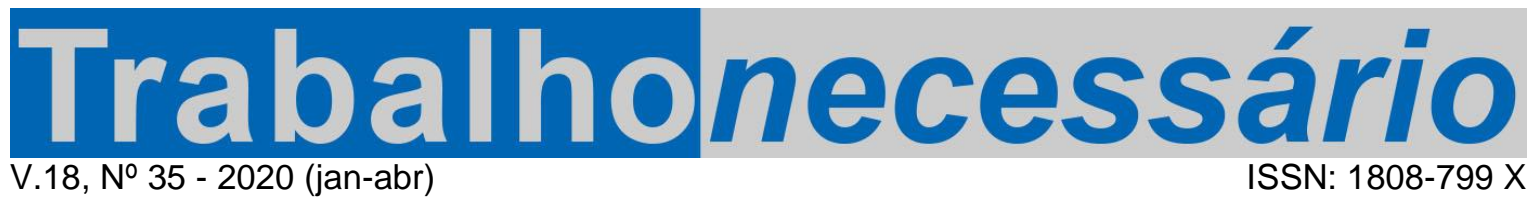

DOI: https://doi.org/10.22409/tn.v18i35.40495

\title{
REFERÊNCIAS HISTÓRICAS E TEÓRICAS PARA A ANÁLISE CRÍTICA DA PRODUÇÃO DO CONHECIMENTO NO BRASIL SOBRE CURRÍCULO INTEGRADO E ENSINO MÉDIO INTEGRADO' ${ }^{1}$
}

\author{
Patrícia Furtado Fernandes Costa ${ }^{2}$ \\ Lucília Regina de Souza Machado ${ }^{3}$
}

Resumo

Neste artigo, busca-se recuperar elementos necessários à análise crítica da história e da produção do conhecimento sobre o debate a respeito do currículo integrado e a oferta do Ensino Médio Integrado a partir de 2004, com o Decreto n. 5.154/2004. Esses temas são importantes para situar teórica e metodologicamente particularidades das contradições entre o capital e o trabalho no contexto das políticas educacionais brasileiras das últimas décadas.

Palavras-chave: Ensino médio integrado; Currículo integrado; Educação; História da Educação Brasileira.

REFERENCIAS HISTÓRICAS Y TEÓRICAS PARA EL ANÁLISIS CRÍTICA DE LA PRODUCCIÓN DEL CONOCIMIENTO EN BRASIL SOBRE CURRÍCULO INTEGRADO Y ENSEÑANZA MEDIA INTEGRADO

\section{Resumen}

En este artículo, se busca recuperar elementos necesarios para el análisis crítico de la historia y de la producción del conocimiento sobre el debate del currículo integrado y la enseñanza media integrada a partir de 2004 con la ley n. 5.154/2004. Esos asuntos son importantes para situar teórica y metodológicamente particularidades de las contradicciones entre el capital y el trabajo en el contexto de las políticas educativas brasileñas de las últimas décadas.

Palabras clave: Enseñanza media integrada; Currículo integrado; Educación; Historia de la educación brasileña.

\section{HISTORICAL AND THEORETICAL REFERENCES FOR THE CRITICAL ANALYSIS OF THE PRODUCTION OF KNOWLEDGE IN BRAZIL ON INTEGRATED CURRICULUM AND INTEGRATED SECONDARY EDUCATION}

\begin{abstract}
This article seeks to recover the necessary elements for the critical analysis of the history and the production of knowledge about the debate about the integrated curriculum and the offer of Integrated High School from 2004 , with Decree no. 5,154 / 2004. These themes are important to situate theoretically and methodologically particularities of the contradictions between capital and labor in the context of Brazilian educational policies of recent decades.
\end{abstract}

Key words: Integrated secondary education; Integrated curriculum; Education; History of Brazilian education.

1 Artigo recebido em 30/06/2019. Primeira avaliação em 23/08/2019. Segunda avaliação em 20/09/2019. Aprovado em 03/01/2020. Publicado em 23/01/2020.

${ }^{2}$ Mestre em Gestão Social, Educação e Desenvolvimento Local pela UNA - BH, Licenciada em Ciências Sociais pela UFJF, professora EBTT no Instituto Federal de Educação Ciência e Tecnologia do Sudeste de Minas Gerais. E-mail: patricia.costa@ifsudestemg.edu.br. ORCID: 0000-0002-48366402.

${ }^{3}$ Doutora em Educação (PUC-SP), Pós-doutora em Sociologia do Trabalho (Iresco-Paris), Professora titular aposentada da UFMG. E-mail: Ismachado@uai.com.br. ORCID: 0000-0001-9029-3019. 


\section{Introdução}

O ensino médio integrado (EMI), modalidade educacional em vigor no Brasil a partir da Lei no 5.154 de 2004, caracteriza-se pela integração entre educação técnica de nível médio e ensino médio de caráter propedêutico. Segundo Frigotto, Ciavatta e Ramos (2012), no ensino médio encontra-se a maior expressão do dualismo da educação brasileira. Nele se evidencia "[...] a contradição fundamental entre o capital e o trabalho, expressa no falso dilema de sua identidade: destina-se à formação propedêutica ou à preparação para o trabalho" ? (FRIGOTTO, CIAVATTA e RAMOS, 2012, p.31).

Para Lima e Sperandio (2017), é no ensino médio integrado que a educação profissional técnica de nível médio pública e de qualidade se encontra. É nele que há a melhor forma de atingir o que preconiza o artigo 205 da Constituição Federal:

A educação, direito de todos e dever do Estado e da família, será promovida e incentivada com a colaboração da sociedade, visando ao pleno desenvolvimento da pessoa, seu preparo para o exercício da cidadania e sua qualificação para o trabalho (BRASIL, 1988).

A Resolução no 6, de 20 de setembro de 2012, dispõe sobre as Diretrizes Curriculares Nacionais para a Educação Profissional Técnica de Nível Médio DCNEPTNM. Ela é uma referência histórica importante para esse debate. No seu segundo capítulo, menciona-se a indissociabilidade entre a educação e a prática social. Neste documento, considera-se a historicidade dos conhecimentos e dos sujeitos da aprendizagem, bem como a integração entre teoria e prática no processo de ensino-aprendizagem.

O debate sobre formação integrada no ensino médio fez emergir conceitos como: formação humana integral e suas várias dimensões, seus obstáculos advindos das contradições sociais, a reposição da dualidade estrutural, a diferença dos itinerários formativos das classes sociais determinada socialmente. O debate trouxe, também, formulações sobre como a integração entre trabalho, ciência, tecnologia e cultura podem contribuir para esta formação humana integral.

Nesse texto, fruto de pesquisa bibliográfica e documental, enunciados e reflexões sobre tais questões, presentes no cenário histórico da educação brasileira das últimas décadas, foram recuperados em razão da sua importância para situar 
teórica e metodologicamente particularidades das contradições entre o capital e o trabalho no contexto e historicidade das políticas educacionais brasileiras. Além de textos acadêmicos, foram também resgatadas as legislações educacionais pertinentes, em especial as do pós Decreto $\mathrm{n}^{0}$ 5.154/2004, que instituiu a possibilidade da oferta de educação profissional técnica de nível médio de forma articulada com o ensino médio, podendo essa ser integrada, concomitante ou subsequente.

\section{Currículo integrado}

Sobre tal conceito, identificam-se ideias bastante diversas no contexto estudado. Logo, serão expostas as que mais se adaptam ao objetivo do artigo apresentado.

Beane (2003), Matos e Paiva (2009) e Santomé $(1988,1996)$ apontaram as disciplinas como objeto para integração. Contudo, há diferenças de interpretação de como realizá-la, pois há os que centram em temas, em competências e saberes ou em diálogo interdisciplinar. Estes autores também se diferem no que tange ao motivo para a integração curricular.

A respeito de quem faz a integração, Beane (2003) ressaltou que os jovens devem ser desafiados por questões pessoais e sociais, que pais e outros cidadãos devem ser envolvidos e que a integração deve ocorrer mediante colaborações. Já Santomé $(1988,1996)$ deixou subentendida a tarefa do "sistema"; porém, salientou a participação conjunta de professores e alunos na integração curricular. Matos e Paiva (2009) não trataram dessa questão.

Matos e Paiva (2009) e Beane (2003) assinalaram que se deve integrar tanto disciplinas quanto experiências. Os primeiros destacaram a integração como estratégia didática de organização dos conhecimentos disciplinares, das competências, dos saberes de referências, das matérias escolares. $E$, ainda, a necessidade de considerar as diferenças existentes entre disciplinas científicas próprias do campo acadêmico e as adaptadas para o contexto escolar.

Beane (2003) considerou a integração como apoio ao crescimento e desenvolvimento saudável dos jovens, visto que ela possibilitaria a promoção de destrezas e atitudes associadas ao modo democrático de vida. Em momento algum mencionou o desenvolvimento crítico do cidadão, que, para Santomé $(1988,1996)$ 
seria seu objetivo maior. Para Beane (2003), a integração acontece utilizando quatro práticas interligadas: o conhecimento do desempenho, o conhecimento organizacional, a criação de comunidades e a construção de relações afetivas. Problemas significativos ou temas ligariam o currículo escolar ao mundo em geral.

Beane (2003) fez essa distinção: antes de 1980, a integração curricular tinha objetivos sociais e democráticos da educação progressista. Após tal década, ela aparece apenas como forma de organizar conteúdos, como técnica. Santomé (1988, 1996) marcou diferença ao afirmar que a interdisciplinaridade é o jeito de se fazer a integração curricular. Mas, para Beane (2003), a interdisciplinaridade diz respeito ao conteúdo, aspecto interno da disciplina e a integração curricular ao aspecto externo à disciplina, ou seja, à problemática.

Santomé $(1988,1996)$ se diferenciou de outros autores citados até aqui, por considerar a integração das diferentes disciplinas por meio do relacionamento interdisciplinar dos conteúdos e, principalmente, por chamar a atenção para a necessidade de se questionar a validade de alguns deles para a compreensão e intervenção na sociedade. A interdisciplinaridade, segundo ele, requer metodologias didáticas baseadas na investigação cooperativa, a construção conjunta, primeiramente pelos professores, depois com a participação dos alunos e, posteriormente, entre docentes e discentes.

Santomé $(1988,1996)$ ressaltou a interdisciplinaridade como maneira de preparar cidadãos e cidadãs para compreender a realidade, sua história, suas tradições e porquês, capacitá-los a intervir e melhorar a sociedade de uma maneira democrática, responsável e solidária. Ciavatta (2012), Ramos (2008, 2009, 2012), Machado (2009) e Lottermann (2012) também demarcaram a relação entre integração curricular e formação crítica dos estudantes.

Para Matos e Paiva (2009, p.14), em convergência com Santomé $(1988,1996)$, "[...] as questões curriculares são percebidas e enfocadas dentro de um projeto de dimensão maior que alcança a sociedade como um todo". Nesse sentido, esse último (1996, p. 64) alegou que se deve "[...] organizar os conteúdos culturais dos currículos de maneira significativa, de tal forma que desde o primeiro momento os alunos e alunas compreendam o quê e o porquê das tarefas escolares nas quais se envolvem". Para ele, isso motivaria os discentes a investigar, indagar e aprender. 
Assim, Matos e Paiva $(2009)$ e Santomé $(1988,1996)$ deram elementos para o debate sobre o objetivo e como fazer a integração curricular. Nela se veria uma maneira de melhorar o processo de ensino-aprendizagem, de possibilitar a compreensão mais reflexiva e crítica da realidade e dos conteúdos culturais.

Santomé ressaltou que fazer a integração curricular por meio da interdisciplinaridade requer a elaboração de estruturas que permitam que os especialistas de cada uma das disciplinas e níveis estabeleçam canais de comunicação e criem espaços para o trabalho em equipe. Segundo ele, os professores precisam "[...] aprender a descobrir nexos entre as disciplinas, detectar que estruturas conceituais, destrezas, procedimentos e valores são mais interdependentes [...]" (SANTOMÉ, 1996, p. 72). Os docentes devem, ainda, criar hábitos intelectuais para a resolução de problemas considerando o maior número de perspectivas possíveis para analisar, avaliar ou intervir. Lembrou da atenção que a educação deve dar às demandas do mundo globalizado. Todavia, segundo ele, estratégias didáticas a partir de um eixo integrador precisam considerar necessidades e interesses individuais, sobretudo, porque os alunos devem analisar, valorar e participar do seu contexto sociocultural e político de forma crítica.

Matos e Paiva (2009, p.12) asseveraram que os defensores da organização disciplinar criticam os currículos integrados alegando que esses desconsideram que cada área do conhecimento "[...] tem conceitos, métodos, formas de raciocínio e de produção do conhecimento próprios e específicos". Diferentemente, eles se colocaram com uma visão próxima à de Santomé, cuja crença no currículo integrado "[...] possibilitaria o entendimento da realidade, sua história e tradições, visando a uma participação social-democrática, responsável e solidária". Contudo, consideraram a possibilidade de que toda organização curricular revela uma dada configuração das relações de poder e, nesse sentido, destacaram que enquanto para alguns, como Santomé, a interdisciplinaridade pode significar uma resposta à efetiva integração curricular; outros pensam que ela pode levar à reprodução de poderes estabelecidos.

Lottermann (2012), tal como Matos e Paiva (2009), também considerou que os currículos carregam representações do poder instituído. Entretanto, ponderou que o currículo integrado é uma proposta de educação contra-hegemônica ao capitalismo, que organiza conhecimentos visando à emancipação dos alunos e o rompimento com fragmentações curriculares instituídas pelas contradições sociais. Associou o currículo 
integrado ao rompimento com o preceito da neutralidade, já que ele demanda a leitura da realidade concreta, o compromisso político e "[...] requer a compreensão de que educar exige interferir em determinada realidade e tomar posição". (LOTTERMANN, 2012, p.22).

Davini também forneceu elementos para o debate sobre currículo integrado. Em obra de 1983, ela argumentou que integrar currículo é articular dinamicamente trabalho e ensino, prática e teoria, ensino e comunidade. Segundo ela, o currículo integrado deve romper com as concepções tradicionais de ensino e com as formas escolares academicistas, com a tradicional divisão entre teoria e prática, que deve ser elaborado com criatividade, ser flexível e adaptado às diversas situações. Na sua visão, o objetivo maior da integração curricular seria o de contribuir com a comunidade. Para tal, seria preciso adaptar o currículo a cada realidade local e aos padrões culturais de uma determinada estrutura social, buscando soluções específicas e originais para seus problemas, fazendo avançar a construção de teorias, envolver professor e aluno na investigação e na busca de esclarecimentos e realização de propostas.

Segundo Davini (1983), o currículo integrado deve ser desenvolvido de forma compartilhada. Inicialmente planejado por educadores, por ela chamados supervisores, esses devem conversar com entidades vinculadas à profissão para a qual se preparam os estudantes e com eles próprios, observar os aspectos do meio social onde a profissão se desenvolve, bem como as características discentes. Assim, durante o processo de aprendizagem, os supervisores junto aos educandos poderão readequar a metodologia, corrigir desvios, avaliar avanços e dificuldades.

Davini (1983) apontou, no entanto, alguns riscos que podem ocorrer na integração curricular: a simples aproximação do ensino ao trabalho não garante integração; pode-se tomar a "realidade do serviço" como parâmetro do ensino desconsiderando-se suas insuficiências; a reprodução sem crítica da realidade pode ocorrer e ainda "[...] o risco de reproduzir assuntos em forma de conhecimentos estanques". (DAVINI, 1983, p. 285).

Lottermann (2012), Machado (2009), Ciavatta (2012) e Ramos (2008, 2009 e 2012) também trataram da integração curricular pelo ângulo da articulação dessas duas esferas, a educação e o trabalho. 
Lottermann (2012) indica para a integração da formação básica com a formação profissional como forma de o trabalhador alcançar, por meio do eixo do trabalho, da ciência e da cultura, o acesso a uma educação abrangente e de diferentes formas de conhecimento - científico, acadêmico, do cotidiano e do senso comum. Ciavatta (2012) também colocou esses três eixos como o núcleo básico do currículo integrado e avançou ao afirmar a necessidade de que a educação geral seja parte inseparável da educação profissional em todos os campos onde se prepara para o trabalho.

Machado (2009) interveio no debate ao afirmar que a integração curricular parte do pressuposto de que conteúdos são tipificados estruturalmente como diferentes, uns seriam gerais ou básicos e outros profissionais ou tecnológicos. Para ela, o importante é discutir os objetivos e finalidades da escola considerando a prática pedagógica no contexto da prática social, tornando os conteúdos concretos ao situar o estudante nas suas diferentes maneiras de se inserir, historicamente, na sociedade e nas relações sociais.

Ramos $(2008,2009,2012)$ também considerou a integração entre o âmbito escolar e a prática social concreta, realçou a integração na perspectiva da formação omnilateral do aluno, considerando todas as dimensões da vida, em especial o trabalho, a ciência e a cultura, eixos assinados também por Ciavatta e Lottermann (2012). Dessa feita, assim como Ciavatta e Machado, Ramos entende o trabalho como princípio educativo, pois tal atividade vital faz do homem produtor de sua realidade e de si mesmo, o que requer considerar a integração dos conhecimentos de formação geral e os específicos como uma relação a ser construída continuamente.

Em comum, Machado, Ciavatta e Ramos associaram a integração curricular às estratégias de superação da dualidade social e educacional. Ciavatta mencionou o propósito da superação da dicotomia trabalho manual/trabalho intelectual para garantir ao jovem, ao adolescente e ao adulto trabalhador o direito a uma formação completa para a leitura do mundo, atuar como cidadão integrado à sociedade e à política, para poder ser também dirigente.

Ramos argumentou que o currículo integrado também é importante como forma de superar a dicotomia entre conteúdos e competências, pois em questão está a necessidade de formar pessoas que compreendam a realidade para além de sua 
aparência fenomênica, que possam atuar como profissionais capazes de reconstruir totalidades por meio da compreensão da relação entre partes. Isso significa:

[...] resgatar a centralidade do ser humano no cumprimento das finalidades do ensino médio e da educação profissional. [...] formar profissionalmente [...] proporcionar a compreensão das dinâmicas sócio-produtivas das sociedades modernas, [...] habilitar as pessoas para o exercício autônomo e crítico de profissões. (RAMOS, 2008, p. 5).

O debate sobre currículo integrado também se voltou para a questão sobre quem se encarregaria de fazer a integração curricular. Ramos não abordou claramente a questão. Lottermann (2012) apontou que essa tarefa cabe aos sujeitos envolvidos na aprendizagem. Para Ciavatta (2012), a integração deve ser objeto de reflexão e de sistematização do conhecimento e que o processo deve acontecer nas escolas, dentro de suas realidades, de forma participativa e mediante decisões coletivas, de sorte que essa tarefa caberia aos "[...] sujeitos sociais coletivos com história e identidade própria a ser respeitada em qualquer processo de mudança". (CIAVATTA, 2012, p. 98). O documento da Semtec/MEC (Ensino médio: construção política) trouxe a recomendação de que as políticas curriculares devem ser "[...] planejadas, vivenciadas e reconstruídas em múltiplos espaços e por múltiplos sujeitos no corpo social da educação". (BRASIL, 2003, p.35).

Para Machado (2009), quem faz a integração são os educadores do ensino médio e do ensino técnico de nível médio, conjuntamente com os alunos. Segundo ela (2009), a experiência educativa tem que ser significativa para o estudante, ele tem que se ver como parte do mundo e que seu mundo seja absorvido pelos conhecimentos científicos. Argumentou que:

[...] é preciso despertar, influenciar e canalizar o desenvolvimento das potencialidades que os alunos e professores trazem e torná-los os sujeitos da construção do processo de ensino-aprendizagem e seus principais e mais severos críticos. [...] Os sujeitos da transformação são as pessoas que se encontram envolvidas no processo com suas necessidades, aspirações e expectativas. (MACHADO, 2009, p.13).

Ao analisar a forma de fazer a integração curricular, Lottermann (2012) alegou a necessidade de se ter um olhar comprometido com a aprendizagem de maneira que a integração curricular possibilite a leitura do mundo, a compreensão do real como totalidade, a reflexão sobre os fatores econômicos, históricos e culturais que permeiam a produção e apropriação do conhecimento técnico. Além de incluir o questionamento do destino do produto social feito pelo trabalhador, como valor de uso 
e de troca, como também a consideração das relações sociais na sociedade capitalista.

Já Ciavatta considerou importante "[...] estender ao ensino médio processos de trabalho reais, possibilitando a assimilação não apenas teórica, mas também prática, dos princípios científicos que estão na base da produção moderna". (CIAVATTA, 2012, p. 88). De acordo com ela, o trabalho se relaciona com a educação nas atividades materiais, produtivas, nos processos de criação cultural, enfim, na vida, e que "[...] a emancipação humana se faz na totalidade das relações sociais onde a vida é produzida. (CIAVATTA, 2012, p. 85).

Esta autora (2012) estabeleceu os seguintes pressupostos para a formação integrada e humanizadora: a existência de um projeto de sociedade, visando à superação da dualidade de classes; manter na lei, a articulação entre o ensino médio de formação geral e a educação profissional; a adesão de gestores e de professores responsáveis pela formação geral e pela formação específica; a articulação da instituição com os estudantes e os familiares, por exemplo, mostrando-se atenta às necessidades e dificuldades dos alunos, à boa infraestrutura na escola; praticar uma democracia participativa como compromisso ético-político; resgatar a escola como um lugar de memória; garantir investimentos na educação.

Ramos $(2008,2009,2012)$ destacou a importância de "teorizar" as atividades práticas, buscando a base científica. Nesse sentido, ela se aproximou de Ciavatta (2012) e Lottermann (2012) ao defender que se deve conhecer a totalidade pela relação entre as partes, fazer com que os conceitos sejam apreendidos dentro da totalidade concreta que se quer explicar, podendo eles ser relacionados interdisciplinarmente ou no interior de cada disciplina. Ramos (2008, 2009, 2012) traçou assim os seguintes passos para a integração curricular: problematizar fenômenos em múltiplas perspectivas como tecnológica, econômica entre outras; explicitar teorias e conceitos fundamentais para a compreensão do objeto estudado; situar os conceitos como conhecimentos de formação geral e específica; organizar os componentes curriculares e as práticas pedagógicas.

As formas de realizar a integração curricular, conforme sugeriu Machado (2009), passam pelo desenho da matriz curricular de forma a contemplar: aproximações temporais; fusões de conteúdos; realização de estudos e pesquisas compartilhados; promoção conjunta de seminários e eventos; implementação de 
métodos de ensino por projetos e por temas geradores. Esta autora destacou que ela deve ocorrer por meio de processos desenvolvidos em comum por todos os envolvidos em que cada ação didática se torne parte de um conjunto organizado e articulado. Para tanto, elencou as seguintes ações didáticas integradas: revisar falsas polarizações e oposições; estabelecer consensos sobre alguns pontos de partida fundamentais (mudanças no modo de agir, formas de articulação dos conhecimentos, diversidade dos processos educativos, práticas pedagógicas); aproveitar as oportunidades, superando as fragilidades do ensino e aumentando a interação entre docentes; trabalhar a unidade dos conhecimentos; revisitar a contextualização sociocultural do processo de ensino-aprendizagem; recorrer aos desafios do desenvolvimento local como recurso significador do currículo; guardar a postura investigativa na definição das alternativas didáticas de integração; explorar as práticas que ajudem a construir o trabalho interdisciplinar.

Machado (2009) defendeu que o currículo integrado se impõe como uma ferramenta fundamental para a construção de uma sociedade mais justa, sem as dualidades estruturais e excludentes, atenta à integralidade do ser humano. Ela reafirmou que a experiência educativa tem que ser significativa para o estudante, para que ele se sinta como parte do mundo e que seu mundo seja considerado na produção dos conhecimentos científicos.

Ciavatta (2012) enfatizou que "A ideia de formação integrada sugere superar o ser humano dividido historicamente pela divisão social do trabalho entre a ação de executar e a ação de pensar, dirigir ou planejar". (CIAVATTA, 2012, p. 85). Ramos (2008) apresentou os dois pilares conceptuais de uma educação integrada: a escola unitária (não dual, garantidora do direito ao conhecimento a todos) e a educação politécnica possibilitando "[...] o acesso à cultura, a ciência, ao trabalho, por meio de uma educação básica e profissional". (RAMOS, 2008, p. 3).

\section{Ensino Médio Integrado}

O debate acerca do ensino médio integrado, tratado nesse artigo, pode ser compreendido historicamente como momento de expressão da capacidade da educação de refletir as contradições sociais advindas de relações sociais assimétricas em todas as épocas. Desde os tempos mais remotos, na Antiguidade Clássica, na 
Idade Média e no atual sistema capitalista, a estratificação social em estamentos e a estrutura de classes sociais definem as segmentações educacionais. A educação formal de trabalhadores passou a ser objeto de atenção apenas com a emergência do capitalismo por conta da necessidade do capital de realizar o controle da cidadania e fazer aumentar a produtividade da força de trabalho e, por conseguinte, incrementar seus rendimentos.

No Brasil, até o século XIX a educação propedêutica era privilégio apenas dos filhos dos grandes proprietários de terra. Por sua vez, a institucionalização da educação profissional teve um sinal tímido de início com a criação do Colégio das Fábricas em 1809. Ocorreram outras iniciativas, todas com a perspectiva assistencialista e direcionadas a órfãos e crianças abandonadas. Em 1909, a criação das Escolas de Aprendizes Artífices objetivou a preparação de operários para o exercício profissional. Desde então, legislações são alteradas, mas sem que, de fato, se modifique o quadro social e educacional da diferenciação entre a formação profissional e a formação geral.

Portanto, o debate sobre ensino médio integrado trouxe à tona a questão da educação integral, um ideal até hoje distante de efetivar-se. A educação profissional permanece com um caráter excludente com relação à formação humana integral, ampla e sólida. Dessa forma, educação geral e educação profissional, cada qual com suas finalidades e objetivos bem diferenciados dentro da estrutura social, vêm concretizando a dualidade estrutural nos sistemas de ensino.

O Manifesto dos Pioneiros, em 1932, foi um sinal de resistência contra essa dualidade. Preconizava que a criança deveria ser iniciada ao trabalho de forma natural. Contudo, nos anos de 1940, a Reforma Capanema reafirmou com as Leis Orgânicas a segmentação na oferta da educação em geral e para o trabalho. Já em 1971, a Lei no 5.692, buscou sem êxito transformar toda a educação de nível médio em profissionalizante. Assim:

[...] a divisão social e técnica do trabalho constitui-se estratégia fundamental do modo de produção capitalista, fazendo com que seu metabolismo requeira um sistema educacional classista e que, assim, separe trabalho intelectual e trabalho manual, trabalho simples e trabalho complexo, cultura geral e cultura técnica, ou seja, uma escola que forma seres humanos unilaterais, mutilados, tanto das classes dirigentes como das subalternizadas. É claro que isso não ocorre de forma mecânica, mas em uma relação dialética em razão das forças que estão em disputa e que, em alguma medida, freiam parte da ganância do capital. (MOURA; LIMA FILHO e SILVA, 2015, p.1059). 
Estes autores mencionados na citação também reintroduziram no debate o questionamento sobre a possibilidade de se ter, numa sociedade capitalista, uma educação correspondente aos interesses da classe trabalhadora, omnilateral. Recordaram o programa proposto por Karl Marx, segundo o qual a:

[...] educação da classe trabalhadora deve compreender: Primeiramente: Educação mental [intelectual]. Segundo: Educação física, tal como é dada em escolas de ginástica e pelo exercício militar. Terceiro: Instrução tecnológica, que transmite os princípios gerais de todos os processos de produção e, simultaneamente, inicia a criança e o jovem no uso prático e manejo dos instrumentos elementares de todos os ofícios. (MOURA; LIMA FILHO e SILVA, 2015, p.1060).

No Brasil dos anos 1980, a proposta da politecnia e da escola unitária marcou presença nas discussões sobre a necessidade de quebrar a dualidade estrutural do ensino brasileiro. Chegou-se a cogitar uma proposta com esse espírito para fazer parte dos dispositivos da Lei de Diretrizes e Bases da Educação Nacional (LDBEN). Contudo, não obteve êxito, permanecendo a educação profissional separada da educação básica.

Assim, em 1996 a nova LDBEN, que nasce sem superar essa dualidade, estrutura a educação brasileira em dois níveis - educação básica e educação superior. A educação profissional aparece à parte, não estando contemplada em nenhum dos dois níveis, demarcando a dualidade de forma bastante explícita (BRASIL, 2007, p. 17). Destarte:

Enquanto o primeiro projeto de LDB sinalizava a formação profissional integrada à formação geral nos seus múltiplos aspectos humanísticos e científico-tecnológicos, o Decreto no 2.208/97 [...] vem não somente proibir a pretendida formação integrada, mas regulamentar formas fragmentadas e aligeiradas de educação profissional em função das alegadas necessidades do mercado. (FRIGOTTO; CIAVATTA; RAMOS, 2012, p.25).

A nova LDBEN foi regulamentada pelo Decreto 2.208, de 17 de abril de 1997. Segundo ele, "[...] o ensino médio retoma legalmente um sentido puramente propedêutico, enquanto os cursos técnicos passam a ser oferecidos de duas formas: concomitante e sequencial" (BRASIL, 2007, p. 19). O projeto neoliberal, do então presidente Fernando Henrique Cardoso (FHC), impôs ao país a perpetuação da dualidade, que passou a ser questionada por diversos setores ligados à educação. 
Esse decreto foi destituído em 23 de julho de 2004 pelo Decreto 5.154, o qual possibilitou a existência do ensino médio integrado ao lado das outras modalidades: a concomitante e a subsequente. Ele determinou que a educação profissional fosse desenvolvida por meio de "[...] cursos e programas de formação inicial e continuada de trabalhadores, da educação profissional técnica de nível médio; e da educação profissional tecnológica de graduação e de pós-graduação" (BRASIL, 2004, s/p).

Formalmente o novo Decreto estabeleceu as condições jurídicas, políticas e institucionais para a oferta do ensino médio integrado. Ele buscou consolidar a base unitária do ensino médio e abranger a diversidade da realidade educacional brasileira. Esse Decreto 5.154 foi de fundamental importância, pois chegou num momento de profunda crise do ensino médio (BRASIL, 2007).

Em 16 de julho de 2008, a Lei 11.741 redimensiona, institucionaliza e integra as ações da educação profissional técnica de nível médio, da educação de jovens e adultos e da educação profissional e tecnológica. Ela possibilita ao educando o acesso ao ensino médio integrado, como também a oportunidade de se preparar tanto para 0 exercício profissional quanto para a continuidade dos estudos.

A instituição da Rede Federal de Educação Profissional Científica e Tecnológica em 29 de dezembro de 2008, com a Lei oㅜ 11.892, cria os Institutos Federais de Educação, Ciência e Tecnologia (IFs). Especializados na oferta de educação profissional e tecnológica nas modalidades de qualificação, ensino médio integrado, cursos superiores de tecnologia e licenciaturas. Eles atuam como instituições de educação superior, básica e profissional, pluricurriculares e multicampi, buscando a interiorização da oferta educacional a partir de cidades-polo, abrangendo o maior número possível de mesorregiões e a sintonia com arranjos produtivos, sociais e culturais locais.

As redes estaduais também foram conclamadas ao desenvolvimento do ensino médio integrado por meio do Programa Brasil Profissionalizado. Entretanto, os meandros para a concretização dessa modalidade de oferta e como o conceito de integração curricular passou a ser interpretado têm servido para mostrar que o debate em torno do assunto permaneceu aberto.

De acordo com o Parecer no 5/11, a educação no Ensino Médio deve possibilitar aos adolescentes, jovens e adultos trabalhadores o acesso a conhecimentos que permitam a compreensão das diferentes formas de explicar o mundo, seus fenômenos 
naturais, sua organização social e seus processos produtivos. Ela deve também, guardar relação com o projeto de vida dos estudantes para que a ampliação, a permanência e o sucesso deles na escola sejam imperativos:

\begin{abstract}
Mais do que o acúmulo de informações e conhecimentos, há que se incluir no currículo um conjunto de conceitos e categorias básicas. Não se pretende, então, oferecer ao estudante um currículo enciclopédico, repleto de informações e de conhecimentos, formado por disciplinas isoladas, com fronteiras demarcadas e preservadas, sem relações entre si. A preferência, ao contrário, é que se estabeleça um conjunto necessário de saberes integrados e significativos para 0 prosseguimento dos estudos, para o entendimento e ação crítica acerca do mundo. (CONSELHO NACIONAL DE EDUCAÇÃO, 2011, p. 40).
\end{abstract}

Segundo o Parecer no 11/12, que apresenta proposições para as Diretrizes Curriculares Nacionais para a Educação Profissional Técnica de Nível Médio, a profissionalização é um direito inalienável do cidadão consagrado no art. 227 da Constituição Federal:

É dever da família, da sociedade e do Estado assegurar à criança, ao adolescente e ao jovem, com absoluta prioridade, o direito à vida, à saúde, à alimentação, à educação, ao lazer, à profissionalização, à cultura, à dignidade, ao respeito, à liberdade e à convivência familiar e comunitária, além de colocá-los a salvo de toda forma de negligência, discriminação, exploração, violência, crueldade e opressão (BRASIL, 1988, s/p).

A Resolução no 6/2012 reafirma a possibilidade de oferta da educação Profissional Técnica de Nível Médio integrada ao Ensino Médio. Apresenta como finalidade proporcionar ao estudante conhecimentos, saberes e competências profissionais necessários ao exercício profissional e da cidadania. Ela guarda como princípios a relação e articulação entre a formação desenvolvida no Ensino Médio e a preparação para o exercício das profissões técnicas, visando à formação integral do estudante; à indissociabilidade entre educação e prática social, à historicidade dos conhecimentos e dos sujeitos da aprendizagem; à interação entre teoria e prática no processo de ensino-aprendizagem, à contextualização, flexibilidade e interdisciplinaridade na utilização de estratégias educacionais favoráveis à compreensão de significados e à integração entre a formação e a vivência da prática profissional. Esta concepção envolve as múltiplas dimensões do eixo tecnológico do curso e das ciências e tecnologias a ele vinculadas; dentre outras. O artigo 14 dessa Resolução destaca o que deve ser proporcionado aos estudantes: 
I - diálogo com diversos campos do trabalho, da ciência, da tecnologia e da cultura como referências fundamentais de sua formação;

II - elementos para compreender e discutir as relações sociais de produção e de trabalho, bem como as especificidades históricas nas sociedades contemporâneas;

III - recursos para exercer sua profissão com competência, idoneidade intelectual e tecnológica, autonomia e responsabilidade, orientados por princípios éticos, estéticos e políticos, bem como compromissos com a construção de uma sociedade democrática;

IV - domínio intelectual das tecnologias pertinentes ao eixo tecnológico do curso, de modo a permitir progressivo desenvolvimento profissional e capacidade de construir novos conhecimentos e desenvolver novas competências profissionais com autonomia intelectual;

V - instrumentais de cada habilitação, por meio da vivência de diferentes situações práticas de estudo e de trabalho;

VI - fundamentos de empreendedorismo, cooperativismo, tecnologia da informação, legislação trabalhista, ética profissional, gestão ambiental, segurança do trabalho, gestão da inovação e iniciação científica, gestão de pessoas e gestão da qualidade social e ambiental do trabalho. (CONSELHO NACIONAL DE EDUCAÇÃO, 2012a, s/p). (negritos não originais).

A Lei no 13.005/14 aprova o Plano Nacional de Educação - PNE, estabelece 20 metas para a educação e traça estratégias para alcançá-las. Dentre as diretrizes está a formação para o trabalho e para a cidadania com ênfase nos valores morais e éticos. Dentre as metas propostas destaca-se a de número onze que propõe triplicar as matrículas da educação profissional técnica de nível médio, assegurando a qualidade da oferta e pelo menos $50 \%$ (cinquenta por cento) da expansão no segmento público. Para tal, estabelece como estratégias: expandir as matrículas na rede Federal; fomentar a expansão da oferta nas redes públicas estaduais; expandir a oferta às populações do campo, indígenas, quilombolas, para pessoas com deficiências e altas habilidades; elevar os investimentos; dentre outras.

Destacam-se neste debate sobre a aprovação do Plano Nacional de Educação - PNE os trabalhos de Moura $(2012,2013)$ e Moura, Lima e Silva (2015) que trouxeram argumentos sobre a necessidade da integração entre a formação humanística e a profissional, entre os conhecimentos gerais e específicos, tendo por base os eixos do trabalho, da ciência, da tecnologia e da cultura. Frigotto, Ciavatta e Ramos (2012) também associam essa integração à formação integral do ser humano. Eles afirmam que "[...] a integração do ensino médio com o ensino técnico é uma necessidade conjuntural - social e histórica - para que a educação tecnológica se efetive para os filhos dos trabalhadores". Alegam que esse é o caminho para a "[...] 
travessia em direção ao ensino médio politécnico e à superação da dualidade educacional". (2012, p. 45).

Araújo (2014) defende a integração entre os saberes e práticas locais com as práticas sociais globais. Lima e Sperandio (2017, p. 144) evidenciam a "[...] integração orgânica dos saberes", das pessoas, dos tempos, dos espaços e dos conteúdos na instituição.

Lima e Sperandio (2017) salientam ser preciso formar um cidadão completo. Argumentam que é necessário que o aluno tenha uma melhor compreensão de si mesmo, do outro, do mundo natural, social, econômico, produtivo e do momento histórico onde está.

Araújo (2014) realça a importância da formação ampla dos trabalhadores como forma de promover sua autonomia e expandir seus horizontes. Revela ser função do ensino médio integrado:

\begin{abstract}
Assegurar aos jovens e adultos que a ele acorrem as ferramentas culturais que permitam aos jovens as habilidades comunicativas, 0 desenvolvimento do raciocínio lógico, os instrumentos para se situarem em seu tempo e em seu contexto social e a construção do pensamento racional-científico, em oposição ao pensamento mágico próprio da infância. (ARAUJO, 2014, p.19).
\end{abstract}

Moura (2012, 2013) e Moura, Lima e Silva (2015) entendem que a função da integração curricular é a de acabar com a dicotomia, com dualidade social e educacional. Para eles é necessário promover o pensamento crítico-reflexivo como forma de compreender as concepções, problemas, crises e potenciais da sociedade e contribuir para a construção de novos padrões de produção de conhecimento, de ciência e de tecnologia. E que é preciso "[...] proporcionar o acesso aos conhecimentos científicos e tecnológicos produzidos e acumulados pela humanidade" com o objetivo de contribuir na formação do trabalhador, intelectualmente autônomo, participativo, solidário, crítico (Moura, 2012, p.4).

Machado (2009, p.1) concorda que é preciso fomentar: um olhar crítico, a habilidade de problematizar e de esclarecer os dilemas apresentados por situações ambivalentes ou por contradições. Somente assim mostrar-se-á cada ação didática como parte de um conjunto organizado e articulado, favorecendo a formação de "[...] pessoas abertas, interessadas, curiosas, críticas, solidárias e de iniciativa”.

Frigotto, Ciavatta e Ramos (2012, p. 42) também destacam que a função maior do ensino médio integrado é a de promover a superação do dualismo. Afirmam que 
"[...] o papel do ensino médio deveria ser o de recuperar a relação entre conhecimento e prática do trabalho". Indicam ser objetivo do ensino médio "[...] propiciar aos adolescentes a formação politécnica necessária à compreensão teórica e prática dos fundamentos científicos das múltiplas técnicas utilizadas no processo produtivo".

Frigotto (2012, p. 78) afirma que a integração busca "[...] alterar as relações sociais que produzem a desigualdade social e assegurar os direitos sociais básicos, entre eles a educação básica, gratuita, laica, unitária, politécnica e universal". Isso concorreria para a construção de um projeto de desenvolvimento com justiça social e efetiva igualdade, a democracia e cidadania substantivas em resposta às imposições das novas bases técnicas da produção e às exigências do trabalho complexo.

Ciavatta (2012) salienta a importância da incorporação da dimensão intelectual ao trabalho produtivo tendo em vista a formação de trabalhadores capazes de atuar como dirigentes e cidadãos. Para fazer essa integração, Araújo (2014) sugere a utilização de projetos e práticas em que cada educador deve se tornar um militante social ativo e ter uma atitude integradora. Já Lima e Sperandio (2017, p. 142) ressaltam que é necessário "[...] melhorar a gestão e ampliar os recursos para a educação" para o ensino não ser tratado como mercadoria e passar a ser um direito, "[...] com acesso gratuito, universal e de qualidade".

Frigotto (2012) enfatiza que, para isso, é preciso proporcionar a materialidade das condições: laboratórios, bibliotecas, material didático, tempo de estudo, formação, condições de trabalho e salário dos professores etc. Machado (2009) acrescenta a articulação criativa das dimensões do fazer, do pensar e do sentir.

Frigotto, Ciavatta e Ramos (2012) defendem a politecnia, o domínio dos fundamentos científicos das diferentes técnicas que caracterizam o processo de trabalho produtivo moderno. Assim, o trabalhador poderá desenvolver diferentes modalidades de trabalho compreendendo sua essência e caráter. Isso significa:

[...] propiciar aos alunos o domínio dos fundamentos das técnicas diversificadas utilizadas na produção, e não o mero adestramento em técnicas produtivas. Não se deveria, então, propor que o ensino médio formasse técnicos especializados, mas sim politécnicos. (FRIGOTTO; CIAVATTA; RAMOS, 2012, p. 42).

A concepção de politecnia diz respeito a uma educação voltada para a superação da divisão social do trabalho existente numa sociedade dividida em classes. Ela representa "[...] incorporar no ensino médio processos de trabalho reais, 
possibilitando-se a assimilação não apenas teórica, mas também prática, dos princípios científicos que estão na base da produção moderna". (FRIGOTTO; CIAVATTA; RAMOS, 2012, p. 42).

Para Moura (2012, 2013) e Moura, Lima e Silva (2015), é preciso considerar os seguintes pressupostos na construção dos projetos político-pedagógicos: construção coletiva (inclusive com pais e representantes da comunidade, docentes); diálogo com os projetos anteriores e o vigente (desafio da mudança e transformação - na forma e na gestão); formação continuada dos dirigentes, docentes e técnicos mediante estratégias de estudos para a reflexão sobre a função da escola.

Lembra Moura (2012) que há diferença entre conhecimento científico e conhecimento escolar. O primeiro precisa ser didatizado para chegar à escola, ser transformado em conhecimento escolar e, nesse processo, muitas conexões se perdem. Para minimizar os prejuízos, seria preciso usar estratégias para se organizar o currículo, globalizadoras e "[...] baseadas em: problemas; centros de interesses; projetos; complexos temáticos; investigação do meio, entre outras". (2012, p. 12). São metodologias que buscam substituir a centralidade das disciplinas pela complexidade das relações da ciência com o mundo real. Entretanto, tais estratégias na prática, apresentam riscos e fragilidades. No ensino médio, existe a necessidade do aprofundamento teórico, visto que cada disciplina "[...] se caracteriza por ter objeto próprio de estudo e método específico de abordagem", o que inviabilizaria a utilização de metodologias globalizadoras. (MOURA, 2012, p. 12).

Santomé (1988) sugeriu a utilização de metodologias mistas, com dois espaços e tempos. Um com atividades integradoras e o outro com o aprofundamento teórico nas disciplinas. Tendo como base os argumentos apresentados, Moura (2012) opta por propor "[...] uma organização por disciplinas (recorte do real para aprofundar conceitos) com atividades integradoras (imersão no ou simulação do real para compreender a relação parte totalidade por meio de atividades interdisciplinares)" (MOURA, 2012, p. 13). Como atividades integradoras, ele sugere as aulas de campo, a elaboração de projetos, a construção de protótipos, a iniciação científica etc., desenvolvidas relacionando o trabalho com situações reais, estabelecendo conexões. Por exemplo, tratando de temas como: "Trabalho/Natureza; Trabalho/Sociedade; Trabalho/Ciência e Tecnologia; Trabalho/Cultura”. (MOURA, 2012, p. 14). 
Araújo (2014) considera que tanto docentes quanto gestores educacionais seriam os responsáveis pela promoção da integração curricular no ensino médio, trabalho que requer ser feito de forma coletiva e colaborativa.

Lima e Sperandio (2017) alertam que apesar de existir vários documentos legais que preveem e amparam a oferta de cursos técnicos integrados, a organização curricular e as formas de acesso não estão explicitados em nenhum lugar. Nesses documentos deveriam conter a forma como deve ser feita a integração, como deve ser gerida, incentivada ou quais atitudes a gestão deve tomar a fim de cobrar dos docentes para que ela seja fortalecida.

Moura (2012, 2013 e 2015); Frigotto (2012); Frigotto, Ciavatta e Ramos (2012) referem-se ao importante papel da legislação para a efetivação do ensino médio integrado como uma política sólida de ensino. Particularmente, os três últimos destacam a

[...] necessidade de as políticas públicas de formação profissional superarem o viés assistencialista/compensatório e promover a inclusão social. Assim, elas devem estar necessariamente articuladas às políticas de desenvolvimento econômico locais, regionais e nacional, ao sistema público de emprego, trabalho e renda [...]. (FRIGOTTO, CIAVATTA e RAMOS, 2012, p. 39).

Moura (2012) chama a atenção para a gestão democrática do projeto políticopedagógico, para a necessidade de participação da comunidade escolar, dos pais e comunidade externa. Frigotto (2012) também defende essa interlocução entre docentes, gestores, educadores e sociedade na gestão de projetos pedagógicos escolares.

Segundo Frigotto, Ciavatta e Ramos (2012), ter a educação básica de nível médio como direito social e universal deve ser a condição para uma formação profissional que possa corresponder às mudanças da base técnica da produção e formar trabalhadores capazes de lutar por sua emancipação. Isto significa praticar a formação profissional não como adestramento e adaptação às demandas do mercado e do capital. Estes autores entendem que a:

[...] formação geral é uma condição necessária para se fazer a "travessia" para uma nova realidade. [...] o Decreto n. 5.154/2004 pretende reinstaurar um novo ponto de partida para essa travessia, de tal forma que o horizonte do ensino médio seja a consolidação da formação básica unitária e politécnica, centrada no trabalho, na ciência e na cultura, numa relação mediata com a formação profissional específica que se consolida em outros níveis e modalidades de ensino (FRIGOTTO; CIAVATTA; RAMOS, 2012, p. 43). 
Frigotto (2012) afirma que a primeira função da escola básica, em especial para os filhos da classe dos trabalhadores, é formar a base dos conhecimentos, valores e estimular as crianças para o aprendizado, para estudar, pensar, se comunicar e viver em grupo. Nesse sentido, Ferreira e Garcia (2012, p. 165) afirmam que "[...] a integração do ensino médio à educação profissional pressupõe a formação de pessoas que compreendam a realidade e que possam atuar como profissionais". Tais considerações são justificadas por Nóvoa (1999) quando diz que: "As democracias dependem da cidadania ativa e consciência clara das nossas responsabilidades sociais. A escola é a melhor instituição que pode cumprir esta tarefa, talvez a única". (NÓVOA, 1999, p.2).

\section{Considerações finais}

Com este artigo, buscou-se resgatar o debate político e pedagógico sobre currículo integrado e ensino médio integrado levado a efeito nas últimas décadas. Essa discussão ganhou grande importância para a história da educação brasileira, especialmente a que concerne à educação profissional, dando ênfase ao pensamento crítico.

As contribuições de diferentes autores serviram de luz aos anseios de todos os que entenderam e entendem que a proposta do ensino médio integrado, considerando o contexto da realidade social brasileira caracterizada por profundas desigualdades sociais, representa uma promessa de grande importância para a efetivação do direito universal à educação integral e de qualidade social.

Por conta dos limites estruturais de um artigo, optou-se por recuperar os elementos principais deste debate para a análise crítica da história e da produção do conhecimento sobre os temas tratados. Reconhece-se, contudo, a grande extensão da produção bibliográfica e documental, fundamentais ao seu acurado e merecido registro histórico.

Com esse artigo, teve-se a intenção de resgatar conceitos fundamentais para situar teórica e metodologicamente as particularidades das contradições entre o capital e o trabalho no contexto das políticas educacionais brasileiras das últimas décadas concernentes ao ensino médio e à educação profissional. 
Isso se faz importante porque as questões que esse debate traz ganha novos desdobramentos por conta das dificuldades que o ensino médio integrado tem encontrado para se efetivar no país. Além da necessidade de se avaliar avanços a despeito da complexidade que essa proposta possui e para conjecturar sobre as perspectivas do seu desenvolvimento futuro em face das implicações trazidas pela reforma do ensino médio instituída pela Lei 13.415/17, que trouxe um novo artigo para a LDB, denominado 35-A. Ele é responsável por vincular os direitos e objetivos de aprendizagem no Ensino Médio à Base Nacional Comum Curricular (BNCC) e em conformidade com áreas do conhecimento.

\section{Referências}

ARAUJO, R. M. L. Princípios do projeto do ensino integrado e finalidades educacionais. In: . Práticas pedagógicas e ensino integrado. v. 7, Capítulo II, p. 43-70, Coleção Formação Pedagógica 1 ed. Curitiba: IFPR - Instituto Federal do Paraná, 2014.

BEANE, J. A. Integração curricular: a essência de uma escola democrática. Currículo sem Fronteiras. Portugal: Universidade do Minho, Braga, 2003. v.3, n.2, p.91-110, jul/dez 2003.

BRASIL. Presidência da República. Constituição da República Federativa do Brasil,1988. Brasília: Senado Federal, Centro Gráfico, 1988. 292 p. Disponível em: <http://www.planalto.gov.br/ccivil_03/Constituicao /Constituicao.htm>. Acesso em: 28 jun. 2016.

. Decreto Federal no 2.208, de 17 de abril de 1997. Regulamenta o $2^{\circ}{ }^{\circ}$ do art. 36 e os arts. 39 a 42 da Lei no 9.394, 20 de dezembro de 1996, que estabelece as diretrizes e bases da educação nacional. Brasília, 1997. Disponível em: <http://www.planalto.gov.br/ccivil_03/decreto/D2208.htm>. Acesso em: 28 jun. 2016.

. Decreto $n^{\circ}$ 5.154, de 23 de julho de 2004. Regulamenta $\circ \S 2^{\circ}$ do art. 36 e os arts. 39 a 41 da Lei no 9.394, 20 de dezembro de 1996, que estabelecem as diretrizes e bases da educação nacional, e dão outras providências. Brasília, 2004. Disponível em: <http://portal.mec.gov.br/setec/arquivos/pdf1/proejadecreto5154.pdf>. Acesso em: 28 jun. 2016.

. Lei Federal no 5.692, de 11 de agosto de 1971. Fixa diretrizes e bases para o ensino de $1^{\circ}$ e $2^{\circ}$ graus e dá outras providências. Brasília, 1971. Disponível em: <http://www2.camara.leg.br/legin/fed/lei/1970-1979/lei-5692-11-agosto-1971357752-publicacaooriginal-1-pl.html>. Acesso em: 28 jun. 2016. 
. Lei Federal no 11.741, de 16 de julho de 2008. Altera dispositivos da Lei no 9.394, de 20 de dezembro de 1996, que estabelece as diretrizes e bases da educação nacional, para redimensionar, institucionalizar e integrar as ações da educação profissional técnica de nível médio, da educação de jovens e adultos e da educação profissional e tecnológica. Brasília, 2008a. Disponível em: <http://www.planalto.gov.br/ccivil_03/_Ato2007-2010/2008/Lei /L11741.htm>. Acesso em: 28 jun. 2016.

Lei Federal no 11.892, de 29 de dezembro de 2008. Institui a Rede Federal de Educação Profissional, Científica e Tecnológica, cria os Institutos Federais de Educação, Ciência e Tecnologia, e dá outras providências. Brasília, 2008b. Disponível em: $<$ http://www.porto.ifto.edu.br:8082/documentos/doc_oficiais/Lei_11892.doc_INSTITU TOS_FEDERAIS.pdf.>. Acesso em: 15 mar. 2016.

. Lei Federal no 13.005, de 25 de junho de 2014. Aprova o Plano Nacional de Educação PNE. Brasília, 2014. Disponível em: <http://www.planalto.gov.br/ccivil_03/_ato2011-2014/2014/lei/l13005.htm>. Acesso em: 10 ago. 2017.

Lei Federal no 13.415, 16 de fevereiro de 2017. Altera a Lei $n^{\circ}$ 9.394, de 20 de dezembro de 1996, que estabelece as diretrizes e bases da educação nacional. Brasília, 2017. Disponível em: <http://www.planalto.gov.br/ccivil_03/_ato20152018/2017/lei/l13415.htm>. Acesso em: 2 abr. 2017.

. Ministério da Educação. SEMTEC. Ensino médio: construção política. In: Seminário Nacional Sobre Ensino Médio: síntese das salas temáticas. Brasília: MECSEMTEC, 2003.

Ministério da Educação. SETEC. Educação profissional técnica de nível médio integrada ao ensino médio. Documento Base. Brasília, dez. 2007. Disponível em: <http://portal.mec.gov.br/setec/arquivos/pdf/documen to_base.pdf>. Acesso em: 15 mar. 2016.

CIAVATTA, M. A formação integrada: a escola e o trabalho como lugares de memória e de identidade. In: FRIGOTTO, G.; CIAVATTA, M; RAMOS, M. (Orgs.). Ensino Médio Integrado: Concepção e contradições. 3 ed. São Paulo: Cortez, 2012, cap. 3 , p.83-106.

CONSELHO NACIONAL DE EDUCAÇÃO. Parecer CNE/CEB no 5, 4 de maio de 2011. Institui as diretrizes curriculares nacionais para o ensino médio. Brasília, 2011. Disponível

em:

$<$ http://portal.mec.gov.br/index.php?option=com_docman\&view=download\&alias=80 16-pceb005-11\&category_slug=maio-2011-pdf\&Itemid=30192>. Acesso em: 18 mai. 2017.

Parecer CNE/CEB no 11, 9 de maio de 2012. Institui as diretrizes curriculares nacionais para a Educação Profissional Técnica de Nível Médio. Diário Oficial da União, Seção 1, p. 98. Brasília, 4 de setembro de $2012 b$. 
. Resolução CNE/CEB no 6, 20 setembro de 2012. Define Diretrizes Curriculares Nacionais para a Educação Profissional Técnica de Nível Médio. Diário Oficial da União. Brasília, 2012a. Disponível em: <http://mobile.cnte.org.br:8080 /legislacao-externo/rest/lei/51/pdf>. Acesso em: 28 jun. 2016.

DAVINI, M. C. Currículo Integrado. CADRHU -Texto Apoio, Brasília, p. 281-289, 1983. Disponível <http://lagarto.ufs.br/uploads/content_attach/path/11340/curriculo_integrado_0.pdf>. Acesso em: 1 mai. 2017.

FERREIRA, E. B.; GARCIA, S. R. O. O ensino médio integrado à educação profissional: um projeto em construção nos estados do Espírito Santo e do Paraná. In: FRIGOTTO, G.; CIAVATTA, M; RAMOS, M. (Orgs.). Ensino médio integrado: concepção e contradições. 3 ed., São Paulo: Cortez, 2012, cap. 6, p. 149-174.

FRIGOTTO, G. A gênese do Decreto n\} 5.154/2004: um debate no contexto controverso da democracia restrita. In: FRIGOTTO, G; CIAVATTA, M.; RAMOS, M. (Orgs.). Ensino médio integrado: concepção e contradições. 3. ed. São Paulo: Cortez, 2012. cap. 1, p. 21-56.

; CIAVATTA, M.; RAMOS, M. Ensino médio integrado: concepção e contradições. 3. ed. São Paulo: Cortez, 2012.

LIMA, M.; SPERANDIO, R. Integração do ensino médio à educação profissional na Rede Federal: obstáculos e viabilidades da integração curricular no IFES. In: Boletim Técnico do Senac, Rio de Janeiro, v. 43, n. 1, p. 140-159, jan./abr. 2017.

LOTTERMAN, O. O currículo integrado na educação de jovens e adultos. 2012. 136f. Dissertação (Mestrado em Educação nas Ciências) Departamento de Pedagogia - Universidade Regional do Noroeste do Estado do Rio Grande do Sul (UNIJUÍ). ljuí, 2012.

MACHADO, L. R. S. Ensino Médio e Técnico com Currículos Integrados: propostas de ação didática para uma relação não fantasiosa. In: MOLL, J. \& Colaboradores. (Org.). Educação profissional e tecnológica no Brasil contemporâneo: Desafios, tensões e possibilidades. Porto Alegre: Artmed Editora S.A.,1. ed., p. 1-17, 2009.

MATOS, M. C.; PAIVA E. V. Currículo integrado e formação docente: entre diferentes concepções e práticas. São João Del Rey, UFSJ, 2009.

MOURA, D. H. A organização curricular do ensino médio integrado a partir do eixo estruturante: trabalho, ciência, tecnologia e cultura. Revista LABOR, Fortaleza, v.1, n. 7, p. 1-19,jul., 2012.

. Ensino médio integrado: subsunção aos interesses do capital ou travessia para a formação humana integral? Educação \& Pesquisa, São Paulo, v. 39, n. 3, p. 705-720, jul./set. 2013.

; LIMA FILHO, D. L.; SILVA, M. R. Politecnia e formação integrada: confrontos conceituais, projetos políticos e contradições históricas da educação 
brasileira. Revista Brasileira de Educação, Rio de Janeiro, v. 20, n. 63, p. 10571080, out/dez 2015.

NÓVOA, A. Entrevista - O futuro é agora. Jornal do Brasil, Rio de Janeiro, 13 jun. 1999, p.2. Caderno: Empregos e Educação para o Trabalho.Disponível em: $<$ https://news.google.com/newspapers?nid=0qX8s2k1IRwC\&dat=19990613\&printsec =frontpage \&hl=pt-BR>. Acesso em: 12 jun. 2017.

RAMOS, M.Concepções do ensino médio integrado. Rio de Janeiro, 2008, 30p. Disponível em: <https://tecnicadmiwj.files.wordpress.com/2008/09/texto-concepcaodo-ensino-medio-integrado-marise-ramos1.pdf>. Acesso em: 4 out. 2016.

. Currículo Integrado. In: Dicionário da Educação Profissional em Saúde. Rio de Janeiro: Fundação Oswaldo Cruz / Escola Politécnica de Saúde Joaquim Venâncio, 2009.

Possibilidades e desafios na organização do currículo integrado. In: FRIGOTTO, G.; CIAVATTA, M.; RAMOS, M. (Orgs.). Ensino médio integrado: concepção e contradições. 3 ed. São Paulo: Cortez, 2012, cap. 4, p. 107-128.

SANTOMÉ, J. T. As origens da modalidade de Currículo Integrado. In: Globalização e Interdisciplinaridade: o currículo integrado. Porto Alegre: Artes Médicas, 1988, cap. 1, p. 1-11.

. A instituição escolar e a compreensão da realidade: o currículo integrado. In: SILVA, Luiz Eron da. Reestruturação Curricular: novos mapas culturais, novas perspectivas educacionais. Porto Alegre: Sulina, 1996, p. 58-74. 